\title{
RANCANG BANGUN SISTEM INFORMASI KONSULTASI AKADEMIK MAHASISWA JURUSAN BERBASIS WEB PADA STMIK PRASTIKOM
}

\author{
Sutrisno $^{1}$, Rohmawati Ningsih ${ }^{2}$ \\ ${ }^{1}$ Dosen Jurusan Teknik Informatika STMIK Raharja, ${ }^{2}$ Mahasiswa STMIK Raharja Jurusan \\ Sistem Informasi \\ ${ }^{1,2}$ STMIK Raharja, Jl. Jenderal Sudirman No. 40 Modern Cikokol - Tangerang \\ e-mail:1 ${ }^{1}$ sutrisno@raharja.info, ${ }^{2}$ rohmawati@raharja.info
}

\begin{abstract}
Abstrak
Dunia pendidikan di perguruan tinggi di harapkan menjadi dunia pengembangan manusia untuk peradaban. Mahasiswa di bekali pengetahuan berupa pendidikan yang dilandasi kebutuhan jaman. Sejalan dengan kebutuhan mahasiswa,tak jarang terdapat mahasiswa yang mengalami kesulitan dalam menyelesaikan matakuliah tertentu. Kesulitan yang bervariasi dimulai dari semester awal hingga semester akhir,kesulitan dalam hal kegiatan belajar di kampus atau bahkan pergaulan dalam lingkungan kampus. Untuk dapat menjawab pertanyaan tersebut dibutuhkan knowledge sharing dan aplikasi yang dapat menjembatani kebutuhan mahasiswa dengan dosen jurusan. Perancangan web ini juga bertujuan untuk memberikan solusi atas permasalahan mahasiswa dan membangun motivasi belajar mahasiswa dalam menyelesaikan pendidikannya tepat waktu. Dengan adanya web konsultasi akademik ini di harapkan dapat membantu pelayanan dosen menjadi maksimal,mahasiswa lebih termotivasi untuk menyelesaikan kuliahnya dan mengurangi tingkat kegagalan mahasiswa dalam menyelesaikan kuliahnya. Metode pengumpulan data yang digunakan pada jurnal ini adalah metode kualitatif, yaitu dengan melakukan observasi, wawancara, dan studi pustaka. Web jurusan ini diharapkan dapat menjadi sarana kedekatan antara dosen dan mahasiswa dalam kaitannya dengan belajar mengajar dan kedekatan antar mahasiswa dalam jurusan yang sama walau berbeda tingkatan.
\end{abstract}

Kata Kunci : Konsultasi akademik,web konsultasi mahasiswa,web jurusan.

\begin{abstract}
The world of education in college is expected to be a world of human development for civilization. Students are equipped with knowledge of education based on the needs of the era. In line with the needs of students, not infrequently there are students who have difficulty in completing certain courses. Difficulties that vary from the beginning of the semester to the final semester, the difficulty in terms of learning activities on campus or even association in the campus environment. To be able to answer these questions required an application that can bridge the needs of students with faculty majors. This web design also aims to provide solutions to student problems and build student motivation in completing their education on time. With the academic consultation web is expected to make lecturer services to be maximal, students are motivated to complete the lecture and reduce the failure rate of students in completing the lecture. Data collection method used in this journal is qualitative method, that is by doing observation, interview, and literature study. With the web majors are expected to be a means of closeness between lecturers and students in relation to teaching and learning proximity between students in the same department although different levels.
\end{abstract}

Keywords: academic consultation, student consultation web, web course. 


\section{PENDAHULUAN}

Pada era modern yang memiliki muatan kemajuan yang sangat tinggi di segala bidang menuntut mahasiswa sebagai penerus bangsa untuk mampu berperan sebagai pembawa perubahan ke arah lebih baik. Untuk dapat mewujudkan harapan tersebut maka mahasiswa dibebani dengan berbagai program di bangku kuliah. Bidang akademik yang berisi inovasi dan teknik pengajaran yang bertujuan untuk meningkatkan kualitas pendidikan[1]. Mahasiswa diberikan kesempatan untuk mengenal dan menjalankan organisasi di dalam kampus yang memberikan pembelajaran bersosialisasi. Dengan banyaknya harapan dan tuntutan pada mahasiswa,tak jarang terdapat beberapa di antaranya yang pada akhirnya tidak dapat menyelesaikan kuliahnya. Dengan beberapa permasalahan yang kompleks ini maka mahasiswa berusaha mencari solusi yang dapat membantu menyelesaikan masalah. Agar solusi yang diharapkan dapat selaras dengan tujuan dalam menyelesaikan pendidikan tepat waktu maka dibutuhkan saran yang membangun dari dosen atau ketua jurusan. Keterbatasan waktu yang dimiliki dosen oleh karna kesibukannya kadangkala menjadi penyebab mahasiswa tidak dapat bertemu secara langsung ditambah lagi dengan jumlah mahasiswa yang begitu besar jumlahnya. Oleh karna alasan di atas maka dibutuhkan suatu cara yang dapat membantu menjembatani mahasiswa dan dosen untuk berkonsultasi. Salah satu solusi untuk memberikan masukan kepada mahasiswa yang ingin berkonsultasi kepada dosen adalah menggunakan Web konsultasi akademik. Aplikasi dibuat dengan menggunakan Macromedia Dreamweaver 8, MySQL dan php.

\subsection{Permasalahan}

Dengan adanya uraian di atas, maka dapat diidentifikasikan masalah sebagai berikut:

1. Bagaimana bentuk rancangan website STMIK PRASTIKOM untuk konsultasi akademik dan tempat untuk meminta saran dan masukan dari ketua jurusan atau dosen pengajar ?

2. Apa manfaat website konsultasi akademik bagi mahasiswa dan dosen?

\section{LANDASAN TEORI}

\subsection{Pengertian Sistem}

Definisi Sistem dapat diihat melalui dua sisi yaitu pendekatan prosedur dan pendekatan komponen, sistem dapat didefinisikan sebagai kumpulan dari prosedur-prosedur yang memiliki tujuan tertentu[2]. Definisi sistem pada sistem informasi dapat di artikan sebagai " komponenkomponen yang saling berhubungan, bekerja sama, untuk mencapai tujuan bersama dengan menerima proses input serta menghasilkan output dalam proses transformasi yang teratur"'[3].

\subsection{Sistem Informasi}

Definisi sistem informasi sebagai perangkat untuk menyajikan informasi agar bermanfaat bagi penerimanya dengan berbagai cara[1]. Tujuan adanya sistem informasi adalah untuk memberi informasi dalam pengambilan keputusan pada perencanaan, pemrakarsaan, pengorganisasian[4]. Sistem informasi dapat didefinisikan dengan mengumpulkan, memperoses, menyimpan, menganalisis, menyebarkan informasi untuk mencapai tujuan. Seperti sistem lainnya, sebuah sistem informasi terdiri atas input (data, instruksi) dan output (laporan, kalkulasi)[5].

\subsection{Pengertian Website}

Website adalah kumpulan halaman web yang saling terhubung [6]. Web memiliki beberapa page atau halaman. Pada umumnya setiap halaman dinamakan homepage yang dibawahnya terdapat childpage yang berisi hyperlink ke halaman lain dalam web[6]. Website yang dapat diakses oleh publik secara kolektif merupakan World Wide Web. World Wide Web atau WWW adalah suatu ruang informasi yang digunakan oleh pengenal global yang disebut Identifikator Sumber Seragam untuk mengenal secara pasti sumber daya yang berguna. WWW adalah bagian dari internet.

\subsection{Pengertian HTML ( Hyper Text Markup Language )}


"Hyper Text Markup Language (HTML) adalah format data yang digunakan untuk membuat dokumen hypertext yang dapat dibaca dari suatu platform komputer ke platform komputer lainnya tanpa perlu melakukan perubahan"[7].

\section{5 Macromedia Dreamweaver}

Macromedia Dreamweaver merupakan program editor membuat website dengan cepat, mudah dan hasilnya pun menjadi sangat menarik dan interaktif'"[7]. Aplikasi yang dibuat memiliki berbagai macam kelengkapan baik tools maupun tampilannya sehingga memiliki waktu pembuatan lebih efektif dan efisien.

\subsection{Pengertian Basis Data}

Kumpulan penyimpanan data yang terintegrasi yang memiliki pengawasan terpusat dinamakan Basis data. Ribuan class dapat tersimpan dalam sebuah basis data yang berupa informasi termasuk di dalamnya class attribute dan relasi antar class[8]Pengelompokan file pada komputer yang saling terhubung juga dilakukan oleh Basis data. Keteraturan File file pada basis data dapat mempermudah pencarian(searching) karna pengelompokan berdasarkan kesamaan elemennya [9].

\subsection{MySQL}

MySQL merupakan turunan salah satu konsep utama dalam basis data yaitu Structured Query Language (SQL) yang diartikan sebagai konsep pengoperasian basis data, terutama untuk seleksi atau pemilihan dan pemasukan data yang memungkinkan pengoperasian data dikerjakan dengan mudah secara otomatis [7].

\section{HASIL DAN PEMBAHASAN}

Sistem konsultasi akademik jurusan Sistem Informasi berbasis web adalah solusi yang diusulkan pada permasalahan yang terjadi. Hal ini berkaitan erat dengan enterprise arsitektur yang sudah di rancang sebelumnya[10].Dengan adanya sistem on line ini diharapkan adanya kedekatan antara sesama mahasiswa dalam satu jurusan tanpa dibatasi oleh jenjang,waktu dan tempat. Keterlibatan ketua jurusan dan dosen menjadi nilai tersendiri untuk meningkatkan motivasi mahasiswa dalam menyelesaikan studinya tepat waktu dan dalam suasana kekeluargaan. Perancangan sistem konsultasi akademik ini dengan menggunakan bahasa pemograman PHP karena PHP adalah bahasa pemograman yang sederhana namun memiliki hasil yang menarik, efektif dan efisien. PHP adalah skrip bersifat server - side yang ditambahkan ke dalam HTML"[2].

\subsection{Teknik Pengumpulan Data}

Pengumpulan data yang dilakukan adalah sebagai berikut :

1. Teknik Observasi adalah pengamatan secara langsung di lapangan. Pengamatan tentang masalah yang diamati dan dinamika proses yang berjalan. 2 . Interview adalah teknik pengumpulan data dengan cara bertanya langsung kepada responden yaitu mahasiswa jurusan sistem informasi. 3. Teknik kepustakaan / Studi pustaka adalah teknik pengumpulan data dengan melalui reverensi buku yang berkaitan dengan masalah yang dihadapi dan solusi yang dapat dilakukan.

\subsection{Use Case}




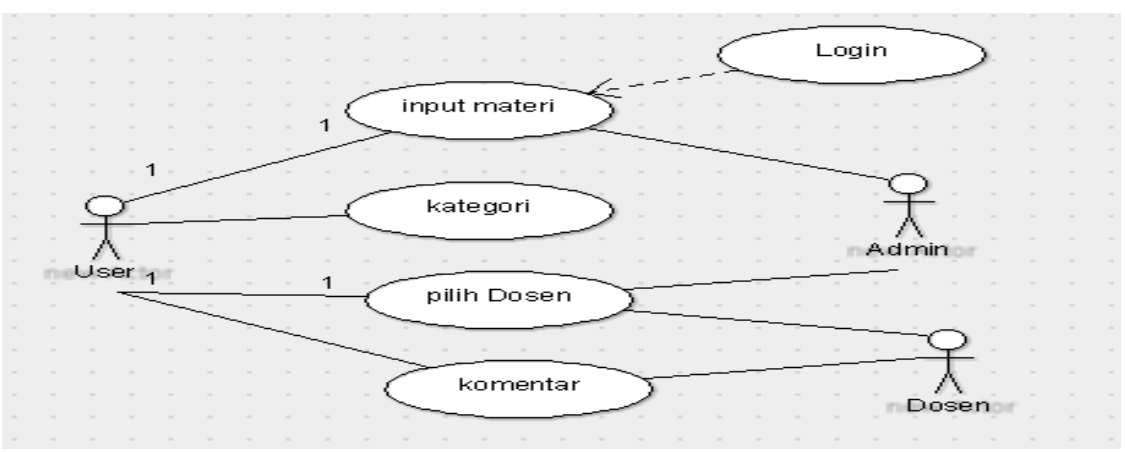

Gambar 1. Use Case diagram

\subsection{Activity Diagram}

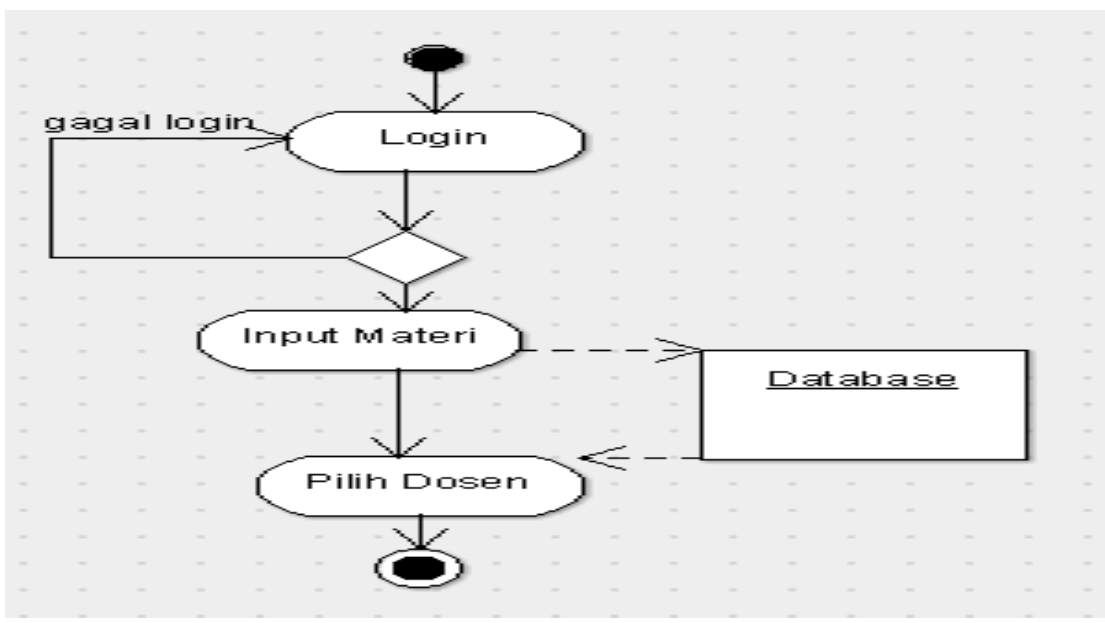

Gambar 2. Activity diagram

\subsection{Class diagram}

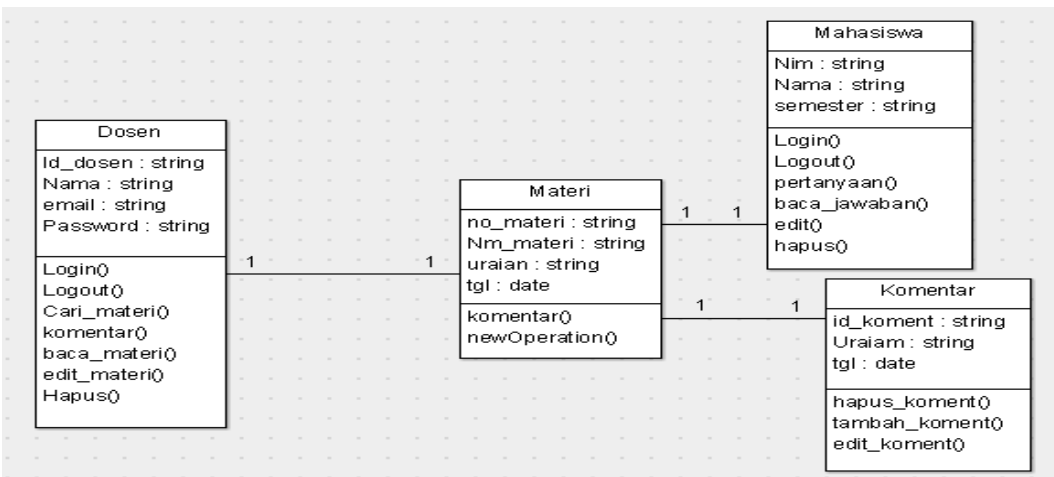

Gambar 3. Class diagram 
3.5 Arsitektur Aplikasi web

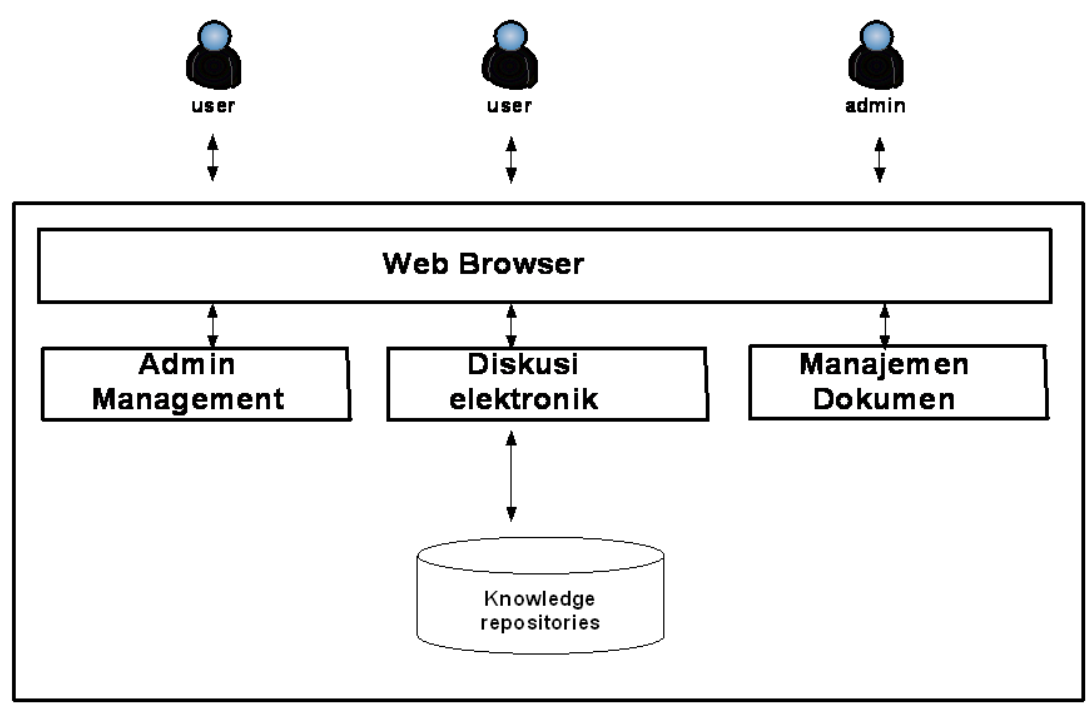

Gambar 4. Arsitektur aplikasi web

\subsection{Rancangan Tampilan}

a. Menu Login

\section{Login}

User Name
E-Mail
Password

User Name

Password

Gambar 5. Menu login 
b. Menu Registrasi Dosen

\section{Prastilom

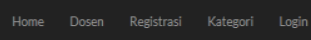

Registrasi Dosen

NIK

Namalengkap

Namauser

Jenis Kelamin

Jurusan

Mata Kuliah

E-Mail

Password

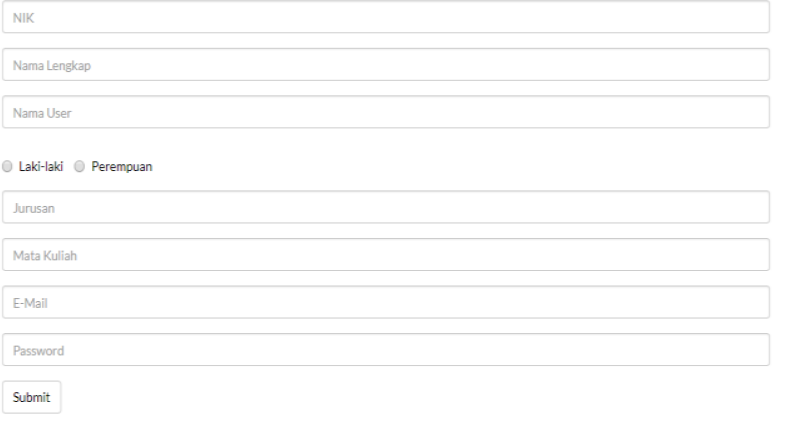

Prastikom

Gambar 6. Menu registrasi dosen

c. Menu Registrasi Mahasiswa

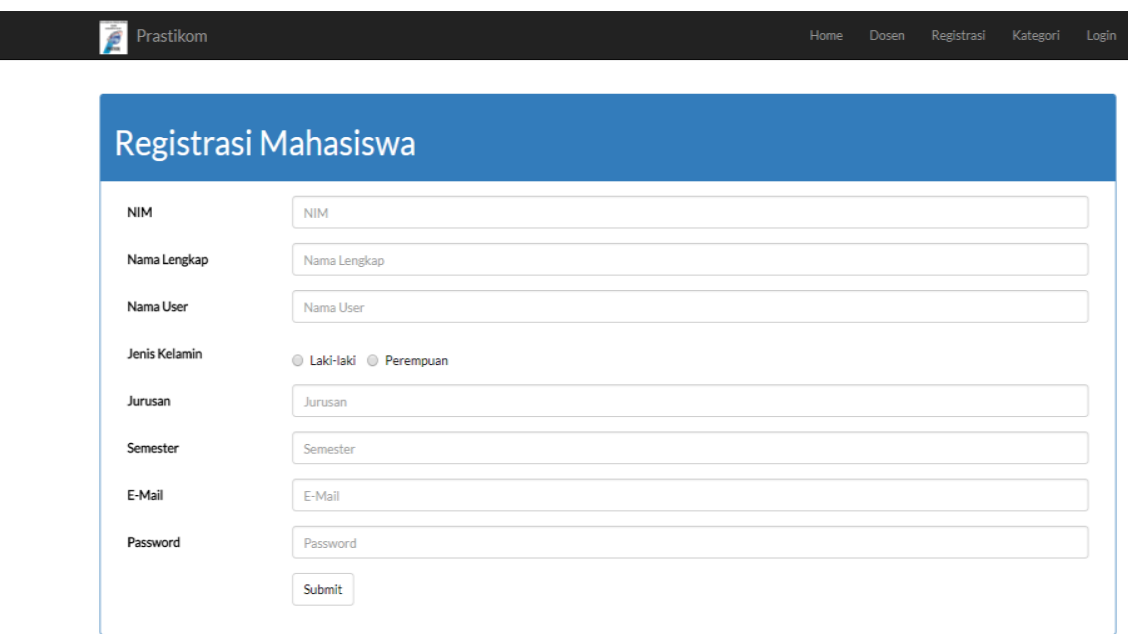

Prastikom

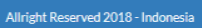

$\theta y+0$

Gambar 7. Registrasi mahasiswa 
d. Menu Kategori

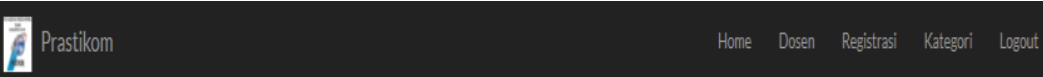

\section{Pilih Kategori}

Konsultasi

- Konsultasi Umum

Konsultasi Mata Kuliah

Submit

Prastikom

Gambar 8. Kategori

e. Menu Form Konsultasi

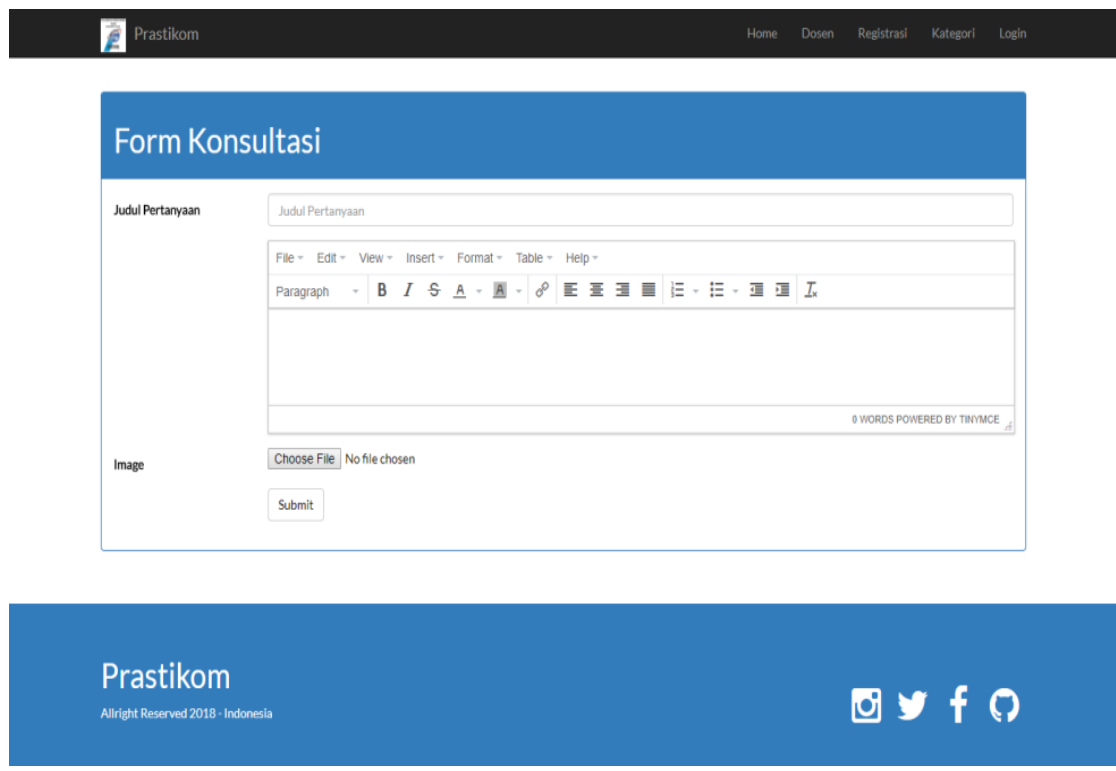

Gambar 9. Menu form konsultasi 
f. Menu Hasil Konsultasi

\section{每 Prasiliom}

Hasil Konsultasi

Insert / Update [Anggota]

No Nama Anggota $\quad$ E-Mail

1 Yudo Trah yudogmail.con

$2 \quad$ Maya Angraeni

$3 \quad$ LarryErico

mayaanggraêvahoo.com

larryellive.com

Tools

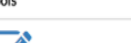

$3 \quad$ Larryerio

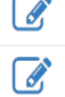

\section{Prastikom}

Gambar 10. Hasil konsultasi

\section{KESIMPULAN}

Sistem informasi konsultasi bagi mahasiswa perjurusan menjadi kebutuhan yang sangat krusial bagi mahasiswa di dalam menunjang keberhasilannya dalam menyelesaikan pendidikan di perguruan tinggi. Konsultasi yang memiliki keistimewaan pada dua menu yaitu konsultasi umum dan konsultasi mata kuliah. Konsultasi umum dapat berupa konsultasi keorganisasian dalam kampus maupun lingkup relasi dengan sesama mahasiswa dalam eventevent yang diadakan antar jurusan. Sedangkan menu mata kuliah adalah berisi konsultasi tentang pencapaian hasil pembelajaran dan saran yang diberikan oleh dosen yang bersangkutan maupun ketua jurusan. Penerapan sistem informasi konsultasi ini juga mampu memberikan manfaat berupa kedekatan antara dosen dan mahasiswa dalam jurusan untuk menghasilkan ide kreatif dalam upaya mengembangkan cara belajar dan mutu pembelajaran.

\section{SARAN}

Sistem informasi konsultasi mahasiswa berbasis web sangat diperlukan bagi mahasiswa khususnya berkaitan dengan konsultasi akademi demi keberhasilan mahasiswa dalam menyelesaikan perkuliahan. Konseling Mahasiswa dengan menggunakan media web dapat merubah pola komunikasi menjadi lebih dekat dan memberikan kenyamanan pengguna dengan suasana kekeluargaan karena melibatkan dosen dan ketua jurusan dan mahasiswa. Dari alasan di atas maka pihak kampus perlu mengembangkan sistem informasi baik media maupun fungsi sistem. Hal ini dilakukan agar tingkat keberhasilan dan kepuasan mahasiswa terhadap layanan kampus menjadi maksimal. 


\section{DAFTAR PUSTAKA}

[1]. Jogiyanto,H.M. Analisis dan Desain Sistem Informasi . Andi, Yogyakarta. 2005

[2]. Kustiyahningsih, Yeni., Devi Rosa Anamisa (2011).Pemograman Basis Data Berbasis Web Menggunakan PHP \& MySQL:Graha Ilmu.

[3]. Agus Mulyanto. 2009. Sistem Informasi Konsep dan Aplikasi. Pustaka Pelajar.Yogyakarta

[4]. Muhammad, Suyanto (2005).Pengantar Teknologi Informasi Untuk Bisnis: Andi Offset.

[5]. Andri Kristanto.2008.Perancangan Sistem Informasi dan Aplikasinya.penerbit Gava Media.Yogyakarta

[6]. Agung, Gregorius, Tips \& Trik Membuat Efek Spesial Website dengan Dreamweaver 4, Elex Media Komputindo, Jakarta, 2002.

[7]. Bunafit Nugroho.2004. PHP \& MySQL dengan Editor Dreamweaver MX, Jakarta: Andi Publisher

[8]. Andi Sunyota. 2007.Pemrograman Database dengan Visual Basic dan Microsoft $S Q L . A n d i$ Offset. Yogyakarta

[9]. Williams, Brian, Stacey C. Sawyer. 2007. Using Information Technology. Salemba Infotek. Jakarta

[10]. Kristiadi Prasetya Dedy,2017, Pengembangan Arsitektur Enterprise Administrasi Pendaftaran dan Operasional Akademik SMK Bonavita Tangerang dengan Metode Zahman Framework, ejournal.istn.ac.id/index.php/incomtech/article/ diunduh tanggal 15 maret 2017 